\title{
LOS DISPOSITIVOS DE LA ENUNCIACIÓN MENEMISTA Y LA TRADICIÓN PERONISTA. UN ANÁLISIS DESDE LA DIMENSIÓN IDEOLÓGICA
}

\author{
Hernán FAIR \\ Consejo Nacional de Investigaciones Científicas y Técnicas \\ (CONICET / CEDIS-UNSAM/Universidad de Buenos Aires) \\ herfair@hotmail.com
}

Resumen: El artículo analiza, desde un enfoque basado en la teoría semiótica de Eliseo Verón, los dispositivos de la enunciación menemista y su relación con el discurso peronista. Enfocando en la dimensión ideológica, pretende dar cuenta de sus diferentes estrategias y modalidades enunciativas en su íntima relación con la enunciación peronista.

Abstract: The article analyses, by a semiotic theory of Eliseo Verón, the discursive strategies from the menemist enunciation and his relation with the peronist tradition. Focusing on the ideological dimension the study pretends investigate the different strategies and enunciation modalities related with the peronist enunciation.

Palabras clave: Discurso. Dimensión ideológica. Enunciación. Menemismo. Peronismo. 
Key Words: Discourse. Ideological Dimension. Enunciation. Menemism. Peronism.

\section{INTRODUCCIÓN}

El tema de la identidad menemista y su relación con la tradición peronista ha sido abordado por una inmensa cantidad de trabajos. Mientras algunos destacan las notables diferencias entre ambos, particularmente en lo que se refiere a sus políticas económicas neoliberales, que contrastarían con el fuerte intervencionismo que caracterizara al peronismo (Borón, 1991, 1995; Portantiero, 1995), y que permitirían hablar de la desactivación de su dimensión populista (Martucelli y Svampa, 1997; Aboy Carlés, 2001, 2003), otros destacan sus semejanzas, principalmente en relación a su estilo de liderazgo personalista (Waisbord, 1995), decisionista (Torre, 1991) y conservador (Giussani, 1990). Menem se habría visto beneficiado, sin embargo, por la nostalgia y el recuerdo en la memoria colectiva de los sectores populares de las políticas del peronismo (Sidicaro, 1995) y por la desactivación de las antinomias del pasado, constituyendo un «neo-populismo» que terminaría con las «identidades por alteridad», reemplazadas por «identidades por escenificación» (Novaro, 1994; Palermo y Novaro, 1996).

Diferenciándose de los enfoques predominantes, este trabajo colocará el eje en la «dimensión ideológica» del discurso menemista y su relación con los dispositivos de la enunciación peronista. En efecto, no se ha analizado aún, con la excepción del trabajo de Paula Canelo (2002), la relación entre las estrategias de la enunciación menemista y las modalidades adoptadas por la enunciación peronista. Esta ausencia de análisis en profundidad del discurso menemista en particular, y de los discursos políticos en general, se condice con la escasa importancia que la Ciencia Política, centrada en el análisis institucionalista y cuantitativista, y en menor medida la Sociología, con su fuerte impronta marxista economicista, le otorgan en general al lenguaje ${ }^{1}$. Se puede sugerir también que la dificultad teórica y conceptual que presentan muchos de los análisis ligados a esta corriente, principalmente en el campo del psicoanálisis y la linguiística de origen saussuriana, han contribuido a su

${ }^{1}$ En relación al enfoque cuantitativista-institucionalista, véase particularmente Sartori (1992). En cuanto a la sociología política marxista-economicista, consúltese, entre otros, el clásico trabajo de Poulantzas (1971). 
modo a alejar el interés en el objeto. Sin embargo, debemos reconocer que en los últimos años ha resurgido el interés por estudiar la importancia que adquiere el discurso en la construcción e institución de eso que llamamos lo social. En efecto, como señala Eliseo Verón, hay niveles de funcionamiento de los procesos políticos a los que sólo podemos acceder a través del análisis del discurso (Verón, 1987a: 14).

Sabemos que a partir de Saussure (1961), el lenguaje comienza a perder su falsa «transparencia». El llamado modelo topológico, que creía, desde Platón, que el lenguaje expresa de manera fiel, objetiva y neutral el pensamiento del que habla, deja, entonces, de tener sentido (Mannoni, 1994: 20-21). A partir de este «giro semiótico» (Fabbri, 2000), tal como lo expresarán múltiples autores, deja de creerse (al menos, en la teoría) en la «unicidad del sujeto hablante». En realidad, lo que existe es lo que Bajtín denomina una «polifonía» de la enunciación, es decir, una «pluralidad de voces que hablan» (Ducrot, 1986: 175). A partir de ahí, como señala Ducrot, no existe un sujeto autor que «habla», sino un acto de producir un enunciado (Ducrot, 1986: 183 y ss.). En efecto, dice Ducrot (1986: 213), «el que emite la enunciación (locutor o narrador) lo hace como responsable de él, pero el discurso puede ser atribuido a enunciadores de los que él se distancia». Tenemos, entonces, que es el acto de producir un enunciado y no el texto del enunciado lo que es el objeto de la semiótica. Esto es lo que Benveniste denomina el «acto de enunciación» (Benveniste, 1980: 86) y Steimberg, en una definición más elaborada, define como el «efecto de sentido de los procesos de semiotización, por lo que en un texto se construye una situación comunicacional, a través de dispositivos que podrán ser o no de carácter lingüístico» ${ }^{2}$ (Steimberg, 1998: 44). Llegamos, entonces, al campo específico de la semiótica, entendida como el estudio de los sistemas y procesos de significación (Steimberg, 1998: 36).

La semiótica, desde Saussure en adelante, tiene como objeto de estudio los signos comprendidos como un todo social. En efecto, para Saussure (1961), la lengua debe ser entendida como un sistema de signos diferenciales en los que la relación de cada uno da significado al conjunto. De este modo, no se estudia el signo aislado, sino en su relación con otros signos. De ahí, su condición de significancia (Benveniste, 1980: 49). En este sentido, señala Saussure, todo signo no sólo es diferencial, sino que también es relacional.

${ }^{2}$ Esto último se relaciona con lo que Verón (1987a) denomina «cuerpo significante». En este trabajo, sin embargo, dejaremos de lado este aspecto del análisis discursivo para centrarnos específicamente en el dispositivo lingüístico. 
Ahora bien, la hipótesis central de lo que llama semiología consiste en señalar que el signo se caracteriza por su «arbitrariedad», esto es, que un significante (palabra o imagen acústica) puede estar asociado a múltiples significados (conceptos concretos) y viceversa (Saussure, 1961) ${ }^{3}$. Con esta definición, el lingüista sentó las bases para el análisis de los sistemas de signos o, mejor aún, de símbolos (Todorov, 1982: 56), que constituye el objeto de estudio de la disciplina denominada comúnmente como semiótica, pero que también ha ejercido gran influencia en el desarrollo de la corriente postestructuralista en su vertiente de psicoanálisis lacaniano y todos sus desarrollos posteriores (Derrida, Badiou, Zizek, etc.).

Existen, sin embargo, múltiples teorías semiológicas, y no todas comparten cada uno de los presupuestos mencionados (véase Fabbri, 2000). En ese sentido, entre las distintas teorías de análisis del discurso existentes ${ }^{4}$, este trabajo partirá desde un marco conceptual basado en el análisis en términos de la «dimensión ideológica» de Eliseo Verón (1987a, 1987b, 1995). Según este autor, todo enunciado se encuentra relacionado con lo que denomina los «dispositivos de enunciación». Esto corresponde a la relación que se establece entre lo que se enuncia y su enunciación. Es precisamente en este ámbito de la enunciación en donde el líder construye la relación de lo que dice con aquello que dice. Así, analizar la dimensión ideológica implica analizar la relación estratégica entre el discurso del «sujeto de enunciación» y sus «condiciones sociales de producción» ${ }^{5}$ (Verón, 1987a; Verón y Sigal, 2003: 19-24).

Desde la perspectiva sociosemiótica de Verón, todo enunciador o, mejor dicho, todo «sujeto de enunciación» ${ }^{6}$, construye una relación discursiva con

${ }^{3}$ En realidad, como bien dice Todorov, más que arbitraria, la relación entre un significante y un significado es inmotivada. De todas maneras, aunque todo signo es inmotivado, su unidad simbólica, esto es, la relación que representa o simboliza, sólo puede ser motivada (Todorov, 1982: 54-55).

${ }^{4}$ Entre otras, se destaca en la actualidad la teoría del discurso de Ernesto Laclau (1987, 1993, 1996, 2005), quien se ha centrado, incorporando elementos del psicoanálisis lacaniano y la deconstrucción derridiana, además de un marco teórico basado en la noción de hegemonía de Antonio Gramsci, en la construcción discursiva de las identidades sociopolíticas a partir de lo que ha denominado la teoría de la hegemonía. Este autor, sin embargo, parecen alejarse parcialmente de la perspectiva de Verón, ya que, si bien comparte la «dimensión polémica» que caracteriza a todo discurso, no analiza estrategias discursivas, sino prácticas articulatorias.

${ }^{5}$ De este modo, esta perspectiva se aleja del análisis de las «ideologías» burguesas que se encontrarían «detrás» de los discursos, como es el caso del análisis de los mitos de Roland Barthes (1991), luego remedado en S/Z (1970). Por el contrario, se trata de interpretaciones que son siempre provisorias y contingentes (Laclau y Mouffe, 1987; Fabbri, 2000: 41).

${ }^{6}$ En efecto, dado que el lenguaje es polifónico, la enunciación es, en realidad, «la instancia de la instauración del sujeto de la enunciación (el sujeto productor del discurso, quien no debe ser confundido con los sujetos de estado y de hacer actualizados en la sintaxis narrativa) que abarca dos posiciones actanciales: la del enunciador y la del enunciatario» (Greimas y Courtés, 1990: 79). 
tres tipos de destinatarios: los adherentes o «prodestinatarios», los indecisos $\mathrm{o}$ «paradestinatarios» y los adversarios o «contradestinatarios». Al tiempo que el enunciador intenta reforzar la creencia presupuesta con los prodestinatarios, ejerce una estrategia de persuasión con los paradestinatarios y, al mismo tiempo, una lectura destructiva con sus contradestinatarios (Verón, 1987a: 17-18). A partir de ahí, el análisis ideológico consiste en examinar las distintas «posiciones del sujeto» en relación a cada uno de estos destinatarios, dando cuenta de las diferentes estrategias políticas a las que apela el enunciador para legitimar sus posiciones (Verón, 1987a, 1987b, 2003). De lo que se trata, a continuación, es de recolectar y analizar un corpus discursivo para dar cuenta de las estrategias del enunciador, a partir del «núcleo invariante» y el «sistema de variaciones» diacrónico del campo discursivo (Verón, 1987a: 14, 1987b, 1995). En pocas palabras, se trata de examinar al menos dos discursos para dar cuenta de sus aspectos inmodificables, los que son modificados y las estrategias que explican esas transformaciones históricas. Para ello, se analiza desde dónde se sitúa y cómo legitima el enunciador lo que expresa frente a sus seguidores, cómo persuade a los indecisos que se encuentran por «afuera» de su propia creencia y, al mismo tiempo, cómo deslegitima el discurso de sus adversarios políticodiscursivos.

Ahora bien, creemos que el análisis del dispositivo de enunciación menemista debe ser acompañado, al mismo tiempo, por lo que algunos autores denominan el análisis de la «semiótica narratológica» (Parret, 1995; Genette, 1998). En efecto, entendemos que toda enunciación lleva implícito un «relato mítico» que la condiciona y legitima. El análisis semiótico de estos relatos resulta particularmente útil, en ese sentido, ya que nos permite revelar, en contraposición a aquellos que creen ingenuamente que la comunicación se basa en la cooperación racional intersubjetiva (Rawls, 1972; Habermas, 1994), que todo discurso, incluso el de la ciencia, implica siempre argumentación y lucha política con otras teorías y otros destinatarios (Parret, 1995; Genette, 1998: 66). En efecto, como han señalado múltiples autores, todo discurso o relato, ya sea el de la ciencia (Verón, 1985; Lyotard, 1992) o el mito (Laclau, 1993), se basa inexorablemente en la polémica y el conflicto con un Otro (Parret, 1995: 64-65; Aboy Carlés, 2001). De este modo, pese a que las huellas de su enunciación son ocultadas, siempre hay en los relatos un autor que es responsable de lo que se enuncia y que intenta imponer implícitamente sus ideas (Segre, 1985: 355; White, 1992; Genette, 1998: 68-70 y ss.).

Este tipo de análisis, al tiempo que nos permite alejarnos de la «ilusión referencial» del liberalismo acerca de la existencia de una supuesta neutrali- 
dad u objetividad independiente de la interpretación (Verón, 1987b; Parret, 1995), resulta particularmente útil para indagar en las estrategias de la enunciación menemista, ya que nos permite dar cuenta de los relatos subyacentes a su identidad política. Específicamente, nos permite investigar la importancia que ejerció el relato de la «cientificidad» de las reformas en la legitimación de su discurso. En efecto, según sostenemos, la enunciación menemista se caracteriza por un tipo de enunciación que se legitima en la «cientificidad» de sus enunciados. Sin embargo, como intentaremos demostrar, no se trata de un discurso de tipo tecnocrático, sino de un tipo de enunciado basado en la legitimación por los hechos.

\section{LA ENUNCIACIÓN MENEMISTA FRENTE AL DISCURSO PERONISTA}

Los hombres hacen su propia historia, pero no la hacen arbitrariamente, bajo circunstancias elegidas por ellos mismos, sino bajo circunstancias directamente dadas y heredadas del pasado. La tradición de todas las generaciones muertas oprime como una pesadilla el cerebro de los vivos.

Karl Marx, El 18 Brumario de Luis Bonaparte

Eliseo Verón y Silvia Sigal han indagado en su libro Perón o muerte. Los fundamentos discursivos del discurso peronista (2003), acerca de la dimensión ideológica del peronismo. Según estos autores, el fenómeno peronista debe ser comprendido como un fenómeno discursivo. Este fenómeno tiene un «dispositivo particular de enunciación» que se caracteriza por lo que ellos denominan el «vaciamiento del campo político» (Verón y Sigal, 2003). Veamos ahora cómo se estructuró este discurso y cuál ha sido su relación con la modalidad de la enunciación menemista.

Según Verón y Sigal, el discurso de Perón se constituyó en base al objetivo último del establecimiento de la unidad nacional (Verón y Sigal, 2003: 48 y ss.). Para ello, principalmente en su última presidencia, apelará al «colectivo de identificación» ${ }^{7}$ más amplio: los «argentinos»:

${ }^{7}$ Desde la perspectiva de Verón, los colectivos de identificación corresponden a un «Nosotros inclusivo», enumerable y fragmentable (por ejemplo, peronistas), mientras que los metacolectivos singulares corresponden a colectivos que no admiten cuantificación o son difícilmente fragmentables (por ejemplo, República) (Verón, 1987a: 18, 1987b, 1995). 
Uno de los postulados más fundamentales de nuestra revolución se ha fijado en la frase que dice: "propugnamos la unidad de todos los argentinos» (Juan D. Perón, 05/08/44. Citado en Verón y Sigal, 2003: 49).

Si analizamos el discurso de Menem, ya desde su asunción como Presidente, notamos la apelación a la necesidad de unidad nacional más allá de las diferencias partidarias. Así, en su discurso ante la Asamblea expresará:

A los jóvenes que no conocieron a nuestro líder y a quienes peinan canas, que sí lo conocieron, yo les quiero expresar que lo que estoy haciendo con la cooperación de todo el pueblo es seguir el mensaje de Eva Perón y de Juan Domingo Perón: la unidad del pueblo argentino por sobre todas las cosas [...]. Ha llegado el momento del reencuentro de todos los argentinos y de todos los habitantes de esta bendita tierra. Ha llegado el momento en que los argentinos nos dejemos de mirar como enemigos para empezar a mirarnos como verdaderos hermanos ante Dios, ante la Patria y ante este glorioso Pueblo. $(08 / 07 / 89: 25)^{8}$.

Además, al igual que su antecesor, utilizará también el «metacolectivo» argentinos para incluir a la comunidad en su totalidad:

Llevo en mis palabras, en mis pensamientos, el único mensaje que nos ha de posibilitar una Argentina grande con un pueblo feliz: la unidad nacional. Por eso convoco [...] para que más allá de nuestras ideologías, de nuestras banderas partidarias, de nuestras pasiones, levantemos a fuego esta unidad nacional $[\ldots](11 / 09 / 91)$.

Les pido que sigamos trabajando juntos, que no dejemos a un lado el afecto y el amor que tiene que existir entre los argentinos [...]. Hoy tenemos en marcha una nueva etapa en la República Argentina, la etapa de la concordia, de la paz y de la felicidad que debemos construir entre todos (15/11/93: 132-133).

Durante su gobierno, Perón insistía en que su único interés era el bien de la Patria (Verón y Sigal, 2003). Así, expresará:

No soy más que un argentino: que no tengo otra ideología que el pueblo de mi Patria, ni otro partido político que mi Patria; y que he de seguir bregando por lo que yo buenamente creo: que es el bien de este pueblo (...) (Juan D. Perón, 10/08/44. Citado en Verón y Sigal, 2003: 62).

${ }^{8}$ Las alocuciones citadas a partir de ahora, salvo expresa aclaración, corresponden a discursos oficiales emitidos por el presidente Menem. 
Del mismo modo, Menem, sin dejar de ser peronista, se situará también como un representante que actúa por los intereses de la Patria en su conjunto:

Este Presidente se mueve a partir de los intereses del conjunto, a partir de los intereses de la República Argentina; no tiene en cuenta los intereses sectoriales en forma absoluta; no tiene en cuenta los intereses de grupos, no tiene en cuenta los intereses de personas [...]. Siempre estuve pensando, y lo reitero, en las futuras generaciones de mi Patria, no en las futuras elecciones [...]. Yo he sido elegido para regir los destinos de la Patria, para conducir a 35 millones de argentinos, y no a los argentinos que integran mi partido o cualquier otro partido de la República Argentina. Soy peronista, sería absurdo tratar de ocultar esta realidad (...) pero procuro, desde mis conocimientos, comprenderlos a todos, y en ese sentido me muevo en este momento (25/04/91: 86).

Este gobierno y este Presidente saben muy bien que no hace cuestiones en el campo de lo ideológico, en el campo de las ideas; no hace referencia a la cuestión de los intereses. Los intereses que estamos defendiendo son los intereses supremos de la República Argentina [...] (09/12/91: 160).

Esto justificará, a su vez, el pragmatismo que, por otro lado, se encuentra inserto también dentro de la tradición peronista:

Tenemos la obligación [...] de seguir incorporando al mayor número posible de argentinos a nuestra causa [...]. No se juega el destino de un partido político, se juega el destino y el futuro de la República Argentina, y la República Argentina nos convoca a todos, absolutamente a todos (12/10/93: 31-32).

Hoy estamos, reitero, reconstruyendo nuestro país y cuando yo necesite de gente que colabore en esta tarea no le voy a preguntar a qué partido político pertenece, sino simplemente le voy a pedir que se comporte como un verdadero argentino y que me ayude a terminar con el desempleo, con la corrupción, con el delito y con aquello que nos ha llevado a una situación harto comprometida a los argentinos (08/07/91: 34).

Cada uno pone su idea, sea de extrema derecha o sea de extrema izquierda, no interesa de dónde, siempre que sea una idea que pueda ponerse al servicio del destino de la grandeza del país (Juan D. Perón, citado en Verón y Sigal, 2003: 90).

Y en ello en razón de que, como decía el General, «Para un argentino no hay nada mejor que otro argentino»"

9 «Para un argentino no debe haber nada mejor que otro argentino. Y lo demás son pamplinas». En realidad, esta frase corresponde a su tercera presidencia. En sus primeros dos mandatos decía, en cambio, 
En ningún momento hemos sido soberbios y les abrimos las puertas a todos los argentinos. No les preguntamos a qué partido político pertenecían. Simplemente hemos convocado a todos para hacer una realidad que decía Perón: para un argentino no debe haber nada mejor que otro argentino. Y esta verdad sigue teniendo vigencia (12/10/93: 30).

Hoy vuelvo como presidente de los argentinos a cumplir un mandato que él (Perón) nos legara: Para un argentino no tiene que haber nada mejor que otro argentino (25/09/91: 224).

Este pragmatismo, que buscaba incorporar a todos los que coincidieran con el proyecto de Menem, terminará legitimando, así, sin contradicción aparente, la integración al Gobierno de figuras que, como los miembros del partido de derecha UCeDé, siempre habían sido acérrimos antiperonistas. Pero, más importante aún, es que velará, al mismo tiempo, la existencia de antagonismos constitutivos:

Ser pragmáticos en la tarea de conducir y gobernar significa subordinar la política a la noción de bien común de la sociedad. Implica liberar a sus miembros del chaleco de fuerza de los compromisos ideológicos al que la habían sometido largas décadas de estéril antagonismo (23/08/91: 136-137).

La estrategia de la enunciación menemista consistía, entonces, en ocultar los antagonismos de manera tal que los diferentes sectores sociales tendían a estar reconciliados entre sí:

Mi Gobierno ha mostrado su voluntad de cambio, de ajustarse a la realidad, de acercar a los empresarios al trabajador, de terminar con los conflictos, para encarar definitivamente un futuro próspero (13/02/92: 38).

El desafío de construir una Argentina integrada. Sin falsas opciones. Sin inútiles enfrentamientos. Sin torpes divisiones [...] Integrar la Argentina es integrar el capital con el trabajo (24/09/91).

Si tenemos en cuenta, con De Ípola (1983), que la primera palabra de todo discurso político asume la forma de una interpelación, resulta interesante notar, en ese sentido, la categoría interpelativa que utilizará Menem en prácticamente todos sus discursos: «Hermanos y hermanas». Esta metáfora despolitizada, de fuerte impronta religiosa, al tiempo que ocultaba las dife-

que «para un peronista no hay nada mejor que otro peronista» (véase Verón y Sigal, 2003). Menem, sin embargo, ignorará esta primera frase, concentrándose, en consonancia con su estrategia de unidad nacional, en la más reciente. 
rencias socioeconómicas, llevaba implícita una concepción basada en la necesidad de «vivir en armonía» y «eliminar todo tipo de conflicto» que alterara la «hermandad» comunitaria:

Ha llegado el momento de la integración, ha llegado el momento de hacer una realidad esto que siempre retóricamente expresamos: el hombre no tiene que ser el lobo del hombre, debe ser el hermano del hombre y, de esta forma, evitaremos males mayores, enfrentamientos, guerras, hambre y miseria (07/10/92: 39).

No se dejen engañar, cada uno de ustedes se tiene que convertir en predicador permanente, a partir del justicialismo, de esta propuesta del Gobierno Nacional y del Gobierno provincial que tiende fundamentalmente a convertir al argentino en hermano de todos los argentinos (22/01/93: 34).

El conflicto, para el enunciador, sólo podía llevar a la disolución social y, por lo tanto, no podía ser aceptado como legítimo. De este modo, se asemejaba nuevamente a Perón, para quien la política sólo había logrado que la Patria se deteriorase (De Ípola, 1983):

Desde lo más profundo de nuestra historia vivimos enfrentados: unitarios y federales, conservadores y radicales, peronistas y radicales, nacionalistas y antinacionalistas, peronistas y antiperonistas. ¿A dónde íbamos con esta propuesta? A nuestra dispersión, a nuestra diáspora, a nuestra pulverización (...). Terminemos de una vez por todas con la prédica disolvente (01/07/92: 28-29).

Deseo hacer un llamado a nuestros partidarios y simpatizantes a fin de que, deponiendo inútiles banderías, estrechen la solidaridad con las demás fuerzas políticas y orgánicamente constituidas (Juan D. Perón, 20/06/73. Citado en Verón y Sigal, 2003: 231).

En ese contexto, el enfrentamiento, y por lo tanto, lo político, sólo podía ser para Menem, al igual que lo era para Perón (Verón y Sigal, 2003), signo de un «absurdo», de «anteojeras mentales» o «ideologismos» sin sentido $^{10}$ :

Abandonando enfrentamientos absurdos, reveladores siempre de anteojeras políticas, mentales y económicas (02/09/91: 168).

${ }^{10}$ En su libro La Revolución Productiva, Menem ya afirmaba: «Hay un conjunto de temas que la sociedad ha consensuado. Sólo es cuestión de desarmar nuestros espíritus de prejuicios, y de sacarnos inútiles anteojeras ideológicas, que deforman los problemas y la realidad» (Menem y Duhalde, 1989: 21). 
Sin falsos enfrentamientos, pero fundamentalmente, recalco esto, sin absurdas pujas ideológicas, que siempre conducen a callejones sin salida (14/10/91: 30).

Sin odios, sin divisiones inútiles, inoperantes e intrascendentes (Juan D. Perón, 20/06/73. Citado en Verón y Sigal, 2003: 231).

Para el enunciador, los que protestan son «infiltrados en las filas de pacíficos militantes», «unos cobardes totales», «enemigos facinerosos que no saben ejercer la democracia», «gente de ultraizquierda», «marxistas», «delincuentes», «activistas de la violencia» (Página 12, 02/01/94 y 04/03/94). Se trata de «Detractores, eternos derrotistas, agoreros del pasado y el fracaso que van perdiendo su lugar en nuestro suelo» (Discurso del 28/08/91). Así, frente a las amenazas de paro sindical, el Presidente afirmará que se trata de «un paro sin motivos, sin propuestas, con fines políticos subalternos, resuelto sólo para satisfacer las demandas de su propio sistema de intereses y de conducción» (Página 12, 05/11/92). El Otro del discurso de Menem tiene, en ese sentido, «intereses políticos», hace política, lo que implica una actitud peyorativa ligada a la persecución de intereses particulares (Yannuzzi, 1995):

Más allá de las futuras elecciones, nuestra obligación es pensar en las futuras generaciones. Es decir, fomentar acuerdos sinceros. Constructivos. Que superen las rémoras absurdas, producto de mentalidades sub-desarrolladas, incapaces de mirar más allá de un rédito político siempre efímero (25/07/91: 66).

Aqui hay muchos intereses en juego, pero alguien tenía que tomar el toro por las astas. No es que esto venga del gobierno anterior, esto viene de muchos años atrás. Pero alguien tenía que dar la cara, poner la cara y recibir las bofetadas, y es necesario recibirlas porque por sobre los intereses de grupos de sectores o intereses particulares, están los sagrados intereses de la República Argentina y los vamos a defender hasta las últimas consecuencias (26/04/91: 95).

Mientras los acontecimientos nos impulsan cada día más hacia el desastre, los argentinos más se aferran a la defensa de sus intereses personales o de círculo [...] ninguno se acuerda de que lo que hay que salvar es el país por sobre todo otro interés mezquino o parcial (Juan D. Perón, 17/10/72. Citado en Verón y Sigal, 2003: 60).

Si el conflicto es un «absurdo» que no tiene razón de ser, lo único que queda es eliminarlo para poder volver a la situación previa de «normalidad»:

A partir de Dios, todos, absolutamente todos los habitantes de este planeta, somos hermanos, y debemos hacer lo imposible para que esa hermandad lle- 
ve a los hombres a vivir en armonía, a eliminar todo tipo de conflicto que imposibilite la realización de las comunidades, y en este ámbito, la realización del hombre, principio y fin de todas las cosas (30/10/91: 57).

Es realmente un absurdo, una arbitrariedad, desde el sector público, desde un sector desde donde se presta un servicio público, declarar una huelga por tiempo indeterminado. Por eso dije que si hay una huelga por tiempo indeterminado, las medidas que tomará el gobierno con los responsables o en contra de los responsables, también serán en tiempo indeterminado. Por eso, vuelvo a llamar a la reflexión a los huelguistas, sean companeros o no, para que levanten el paro y entraremos a dialogar. Caso contrario, lamentablemente, con mucho dolor, seguirán saliendo los telegramas de despido hasta que normalicemos esta situación (25/03/91: 48-49).

De este modo, al igual que Perón, que situaba su acción como un servicio, como un simple soldado que no quiere nada para sí mismo y que sólo está movido por el interés de la Patria y llega para servir al Pueblo (Verón y Sigal, 2003: 33 y ss.), el discurso menemista también negará la presencia de intereses políticos. Ahora bien, como señalan Verón y Sigal, Perón lograba legitimar su posición anti-política situándose por afuera de la misma en tanto «enunciador abstracto» que llegaba en una «hora grave» proveniente de un ámbito «apolítico» como era el cuartel con el único propósito de servir a la Patria. Así, lograba constituirse discursivamente como encarnación del Pueblo y, al mismo tiempo, excluir a sus adversarios por ser el Anti-Pueblo o la Anti-Patria. En su tercera presidencia, el «modelo general de la llegada» era ahora proveniente de un exterior geográfico, representado por el exilio. Perón ya no representaba al Pueblo, sino a la Nación. El dispositivo de enunciación, sin embargo, se mantendrá vigente (Verón y Sigal, 2003) ${ }^{11}$.

11 El funcionamiento del «modelo de la llegada» estaba asociado a la estrategia de Perón, quien salía del cuartel movido por el sentido del deber ineludible de reestablecer la justicia en la sociedad. Su llegada a la política era el encuentro de los valores inmutables de la institución militar, íntimamente ligados al servicio y defensa de la Patria y el Pueblo, con los valores degradados de la sociedad civil. Perón se situaba como «enunciador abstracto» de la Patria a través de la unión de los colectivos singulares: Ejército, en tanto «humilde soldado», y Pueblo, como «Primer Trabajador». Como ser peronista era igual a ser argentino, los contradestinatarios eran excluidos del campo político y situados, irremediablemente, en el plano de la «Antipatria». Durante su última presidencia, el modelo de llegada era desde el exilio y marcaba un cambio en la estrategia discursiva. Ahora el líder aceptaba la idea de que había diferentes formas de entender y de servir a la Patria. Puesto que las diferencias entre peronistas y no peronistas eran de grado y de opinión, pero no de oposición, los diferentes partidos debían colaborar en la tarea de Unidad Nacional. De este modo, los paradestinatarios no peronistas lograban ingresar en el «nosotros» argentinos. Sin embargo, las divisiones antipatrióticas no desaparecieron, sino que se trasladaron desde fuera del peronismo hacia el interior del movimiento. En este sentido, Verón y Sigal concluyen que el «vaciamiento del campo político» continuará presente, en tanto seguirá vigente el enfrentamiento con un otro Antipatria que es vaciado de toda legitimidad (véase Verón y Sigal, 2003: 29-97). 
Si Perón construyó un «modelo de la llegada» que se mantuvo inalterable, y esto lo legitimaba para negar que hacía política, Menem también «llegará» en lo que Verón y Sigal denominan un «momento fuerte» (Verón y Sigal, 2003: 42), en este caso, representado por el caos del alfonsinismo:

No existe otra manera de decirlo: el país está quebrado, devastado, destruido, arrasado. El legado que estamos recibiendo es el de una brasa ardiendo entre las manos. El de una realidad que quema, que lacera, que mortifica, que acosa, que urge solucionar. La inflación llega a límites escalofriantes [...]. El hambre, moneda corriente para millones de compatriotas. El desempleo, una enfermedad que se cierne sobre cada vez más amplios sectores de nuestra comunidad. El dolor, la violencia, el analfabetismo y la marginalidad, golpean a la puerta de nueve millones de argentinos.

Estamos viviendo una crisis dolorosa y larga. La peor. La más profunda. La más terminal. La más terrible de todas las crisis de las cuales tengamos memoria.

Estamos en una auténtica situación de emergencia económica y social (08/07/89: $11-13$ y 17).

En efecto, el presidente Menem asumirá el poder seis meses antes de que finalice el mandato de su antecesor, el radical Raúl Alfonsín (1983-1989), en medio de una hiperinflación inédita en la historia del país, con índices que llegarán a 114,5\% en junio, sumando un total de $613 \%$ en sólo 6 meses y saqueos de alimentos a supermercados y comercios en cientos de barrios pobres del país ${ }^{12}$.

Su discurso, sin embargo, no se constituirá, como algunos sostienen, en una «nueva versión del modelo de llegada» (Canelo, 2002: 12) o en un «outsider» de la «clase política» (Novaro, 1994; Palermo y Novaro, 1996: 207), rol que difícilmente podía compatibilizar con su pasado de dirigente político. En efecto, el sujeto de enunciación se había incorporado al peronismo en 1958, siendo electo por primera vez como gobernador de La Rioja en 1973 (Nun, 1994: 84). Además, como no dejará de recordar, su propio pasado como político lo había llevado a estar 5 años en prisión durante la dictadura del '76. De todos modos, y al igual que Perón, se situará por fuera de las ideologías e intereses sectoriales o partidistas ${ }^{13}$ :

12 Para un análisis más detallado del particular, véanse Fair (2007 y 2008).

13 Este hecho se encuentra íntimamente ligado a la crisis de los partidos políticos (al respecto, véase, entre otros, Cheresky y Blanquer, 2003) y de la propia actividad política (véase Cavarozzi, 1997: 127-128). 
Hemos resuelto dejar a un lado los ideologismos. Yo vengo sosteniéndolo desde hace mucho tiempo. La patria no tiene ideologías, los partidos y los movimientos, sí; la patria tiene intereses, y por sobre los intereses de la patria, de esta querida República Argentina, nada superior, nada de ideología (01/09/89: 54-55).

Deseo dirigirme hoy a cada uno de los argentinos, para formular una convocatoria sincera. Amplia. Generosa. Despojada de todo tipo de interés sectario o de especulación mezquina (07/01/93: 15).

Soy un austero soldado que no tengo ambiciones ni las tendré nunca (Juan D. Perón, 15/10/44. Citado en Verón y Sigal, 2003: 31).

Para ello, apelará en reiteradas ocasiones a las metáforas organicistas ${ }^{14}$, inscriptas dentro de la tradición peronista, afirmando que era necesario hacer «cirugía mayor sin anestesia» con el objeto de «sanar» al «cuerpo» social:

Sería un hipócrita si lo negara. Esta economía de emergencia va a vivir una primera instancia de ajuste. De ajuste duro. De ajuste costoso. De ajuste severo [...]. Una cirugía mayor que va a extirpar de raíz males que son ancestrales e intolerables (08/07/89: 17-18).

Cuando yo me hice cargo del Gobierno, quiero refrescar la memoria a todos los argentinos, dije en el Parlamento argentino que recibía una Argentina arrasada por la corrupción y que íbamos a hacer cirugía mayor sin anestesia. Los hechos me están dando la razón, pero nada ni nadie nos va a parar hasta que no sanemos definitivamente el cuerpo de la República (25/04/91: 90).

El mismo microbio que entra, el germen patológico que invade el organismo fisiológico, genera sus propios anticuerpos, y esos anticuerpos son los que actúan en la autodefensa. En el organismo institucional sucede lo mismo. Cuando se dejan actuar los gérmenes patógenos, que también los hay, al entrar en el cuerpo orgánico institucional, generan también sus anticuerpos (Juan D. Perón, 08/11/73. Citado en De Ípola, 1983: 144).

Como decía Walter Benjamin, «la idea de sacrificio no puede imponerse sin la idea de redención» (Benjamin, 2004: 33). En este caso, el «sacrificio» venía de la mano de los ajustes estructurales de la economía y la «redención»

${ }^{14}$ Como señala Borón, Menem, al igual que Perón, entiende a la sociedad como un «organismo natural» en el que «sus partes deben convivir armónicamente, pues de lo contrario se corre el riesgo de la anarquía y la disolución nacional». En este sentido, «el conflicto social expresa las ocasionales desinteligencias producidas por el choque de intereses personales, pero no existen contradicciones estructurales ni antagonismos irresolubles» (Borón, 1991: 62). 
era un futuro de bienestar social. Su eficacia, sin embargo, residía en que los ajustes eran reemplazados por la metáfora de la «cirugía mayor sin anestesia». Esta necesidad de «operar» simbolizaba desde el sentido común el «sacrificio» conjunto que, pese al «dolor» que causaba, era inevitable que llevara a cabo la sociedad para lograr un futuro venturoso o, desde la metáfora organicista del discurso menemista, para «salvar» al «cuerpo» social de la República que se hallaba en «terapia intensiva». En palabras de Menem:

Cuando yo me encontré con este estado de cosas dije: Señores, se acabó. Cirugía mayor sin anestesia, para hacer saltar la materia que estaba enquistada en el cuerpo de la República Argentina. Aquí están los resultados; con mucho dolor, pero una Argentina que crece. Con mucho sacrificio, pero una Argentina ordenada (21/08/93: 201).

Queda claro, entonces, que el enunciador, al igual que siempre lo había hecho el peronismo, intentará excluir desde su discurso a sus adversarios políticos. Pero, ¿cómo legitimará la exclusión discursiva de sus «contradestinatarios»? (Verón, 1987a, 1987b). Si Perón excluía a sus enemigos por ser el legítimo representante del Pueblo, un primer análisis puede señalarnos que Menem lo hacía del mismo modo ${ }^{15}$. No obstante, ello no nos conduce a explicar cuál era su dispositivo específico. Una explicación más elaborada podría ser que el líder apelará a un discurso científico que excluirá a sus adversarios por estar fuera del «sentido común» ${ }^{16}$. En efecto, el sujeto de enunciación justificará su discurso afirmando que las políticas económicas que él implementaba se efectuaban por el bien del país. Así, expresará:

Todas estas transformaciones están marcando a sangre y fuego el cambio que nos hemos impuesto desde el principio. Yo dije «cirugía mayor sin anestesia»; lo estamos haciendo y no vamos a cesar en nuestro empeño hasta que demos cumplimiento al objetivo que nos hemos trazado [...]. No nos interesan las futuras elecciones, sino las futuras generaciones y el futuro de la República Argentina. Por eso estamos trabajando de esta forma, sin ningún tipo de claudicaciones, sin bajar los brazos, sin desfallecer, firmes, seguros, reflexivos, serenos. De lo que hagamos depende la suerte y el futuro de la República Argentina (14/01/91: 18-19).

15 Así, Palermo y Novaro (1996: 132) consideran que, mientras que Alfonsín firmó un pacto, el peronismo, y Menem se inscribe en esa lógica, no lo requiere, ya que «él mismo es el pueblo».

${ }^{16}$ Como señalan Verón y Sigal (2003), «el discurso científico se estructura de modo diferente al discurso político». En lugar de decir «creo en», afirma «verdades eternas». Es decir, que se ubica «afuera de la creencia», situándose como una «verdad objetiva e indiscutible». Así, «estoy indicando a mi interlocutor que no puede rechazar mi afirmación sin correr el riesgo de quedar fuera del «sentido común» (2003: 23). Este tipo de discurso que formula una «verdad universal e intemporal» también ha sido denominado por Verón como discurso «didáctico» (Verón, 1987a: 21). 
Este Presidente ha puesto la cara y va a seguir poniendo la cara, pese a todo y contra todo, con tal de resguardar los intereses de la República Argentina (05/08/91: 96$)$.

De este modo, el Presidente se mostraba ante la sociedad con intereses propios que se ponían fuera de toda discusión y como garantía de que las cosas se hacían por «necesidad» y no por razones doctrinarias:

Si nosotros hubiéramos estado obrando ahora con un criterio meramente electoralista pensando en las elecciones de este año, no hubiéramos tomado una serie de medidas que son dolorosas pero necesarias, cirugía mayor sin anestesia, porque lo que importa es el país y no las elecciones (31/01/91: 34).

Los argentinos debemos sufrir de una sola vez para dejar de sufrir toda la vida, para ser felices y hacer una Patria grande, con un pueblo feliz [...] Nadie quiere la Argentina del ajuste por el ajuste mismo. Yo me quiero sincerar: este ajuste es para terminar con la Argentina de la decadencia, con la Argentina del estancamiento, con la Argentina de la corrupción (08/07/91: 35).

Al mismo tiempo, colocaba toda intencionalidad, connotación siempre de una fuerte carga negativa, en la persona del adversario (Yannuzzi, 1995: 168-169):

Yo les pido desde lo más profundo de mi corazón [...] que no hagamos de esto una cuestión ideológica; que dejemos los ideologismos de lado y pensemos fundamentalmente en nuestra patria (28/05/91: 144).

Sin preconceptos ideologizados. Sin ataduras dogmáticas. Sin frivolidades intelectuales, ignorantes, en el fondo, de la actual realidad mundial (19/07/91: 54).

Podemos decir, entonces, que el enunciador logrará relegitimarse apelando a un discurso tecnocrático ${ }^{17}$, que prometía el reemplazo de la política, que sólo hacían sus adversarios, por la «pura administración razonable» (Hilb, 1994). Así, despolitizando el ámbito público, lograba legitimar las reformas y a su propio discurso, al tiempo que excluía el disconformismo como expresión de intereses particulares o partidistas. Ahora bien, si analizamos con más cuidado, podemos observar que la hipótesis del discurso tecnocrático resulta inadecuada. En efecto, el discurso de Menem no cum-

17 Según Verón (1985), la estrategia a la que apela el discurso tecnocrático consiste en «jugar el juego de la política mientras parece jugar a otro juego». No obstante, si bien parece excluir los antagonismos que caracterizan a toda identidad política, es con los propios políticos con quienes antagoniza. 
plirá las «condiciones de felicidad» (Austin, 1998) que requiere todo discurso que se precie de tal, esto es, la eliminación de todo rasgo de presencia de los «colectivos de identificación» (Verón, 1985, 1995). En el caso de Menem, hay un intento de traspasar ese vínculo. Sin embargo, la constante apelación discursiva a la tradición peronista y la reivindicación de su pasado como militante y luego dirigente político, nos obliga a rechazar esta presunción. Por otra parte, en el discurso de Menem no existirá la indispensable separación entre la esfera de la economía y la esfera de la política, propias de este tipo de discurso «antipolítico». Así, el enunciador definirá a la política, en el sentido aristotélico, como «la ciencia de las ciencias que tiende al bien común» (Discursos del 08/07/92: 45 y 15/09/92: 236) y, al mismo tiempo, expresará: «Lo político con lo económico, lo político conduciendo al país y a la economía» (Discurso del 07/07/93: 43). Y también: «No se puede considerar la política y la economía como compartimentos estancos. Cuando funciona la política, funciona la economía» (Clarín, 24/01/93).

Plantearemos, entonces, una tercera hipótesis: sostenemos que el elemento clave que estructurará el discurso menemista será el Plan de Convertibilidad, que se transformará en una «Promesa Plena». Para entender esta cuestión, sin embargo, debemos ubicarnos previamente en el contexto de emergencia de su liderazgo.

\section{CONTEXTO DE EMERGENCIA DEL LIDERAZGO MENEMISTA}

Como dijimos, el presidente Menem asumirá en medio de un caos político, económico y social, la herencia del gobierno de Alfonsín (Martínez, 1991). En ese contexto, y mientras muchos de sus votantes esperaban el «Salariazo» y la «Revolución Productiva» prometidas durante la campaña electoral ${ }^{18}$, el Presidente emprendió el rumbo contrario. Con el respaldo de los grandes empresarios y también de los Estados Unidos, con cuya política exterior se alineó al punto tal de constituir «relaciones carnales», se dedicó a aplicar el recetario neoliberal. Como consecuencia, se asistirá en esos años a una verdadera reestructuración económica y social que terminará por descomponer la antigua «matriz estadocéntrica» (Cavarozzi, 1997). Esta matriz,

18 Durante la campaña presidencial, Menem afirmaba que iba a implementar una Revolución Productiva que terminaría con la especulación y un «salariazo» que iba a consolidar el mercado interno (véase Clarín, 25/02/89 y 26/02/89 y la Solicitada del 12/05/89). Al respecto, cfr. también Menem y Duhalde (1989). 
que se remontaba a la posguerra, se caracterizaba por la presencia de un Estado que intervenía fuertemente en el mercado para regularlo y asignar bienes y servicios a través de una política industrializadora basada en la sustitución de importaciones (Torrado, 1994). En su reemplazo, se consolidará un nuevo modelo de acumulación, un programa que venía implementándose de manera creciente desde mediados de la década del setenta (Basualdo, 2006).

A pesar de esta metamorfosis en relación a las banderas tradicionalmente asociadas al peronismo, el Presidente logrará evitar una ruptura inmediata e incluso mantendrá el respaldo en gran parte de los principales afectados, los sectores populares. ¿Qué es lo que permitió este apoyo popular? Algunos autores sostienen que la clave residió en el contexto de fuerte pérdida de legitimación del gobierno anterior, producto del caos hiperinflacionario, lo que habría posibilitado un «estado de disponibilidad» social. En esa situación, definida como «consenso de fuga hacia adelante», Menem habría obtenido el respaldo de una heterogénea coalición social a partir de constituirse en un liderazgo decisionista que garantizaría orden, seguridad y certidumbre (Palermo y Torre, 1992; Novaro, 1994; Palermo y Novaro, 1996). Para otros, en cambio, se trató más bien de un «discurso hobbesiano de superación del caos», que transformó al menemismo en el «Partido del Orden» (Aboy Carlés, 2001, 2003).

Ahora bien, sin dejar de reconocer la importancia que tuvo el temor al regreso a la hiperinflación para legitimar el discurso menemista, debemos recordar, en primer lugar, los vaivenes con los que tendrá que lidiar su liderazgo hasta lograr la estabilización efectiva de la economía. En efecto, durante los primeros 18 meses los diferentes ministros de economía tratarán sucesivamente de controlar la inflación con diferentes medidas (Lozano y Feletti, 1991). El Gobierno, sin embargo, no logrará dominar del todo la inflación, e incluso experimentará dos nuevos episodios hiperinflacionarios, a fines de 1989 y de 1990, que terminarán de hacer ineficaces muchos de los tradicionales instrumentos de política económica (Fair, 2007, 2008). En ese contexto, podemos decir, con Canelo, que el «consenso de fuga hacia adelante» en realidad durará poco (Canelo, 2002: 18).

Por otra parte, a diferencia de esta perspectiva, creemos que el control definitivo de la hiperinflación, si bien necesario para constituir su liderazgo, resultará insuficiente para consolidarlo. Para alcanzar ese objetivo, sostenemos, en cambio, que el elemento crucial será el éxito en la implementación del Plan de Convertibilidad. Este Plan, como veremos, le permitirá al Presidente satisfacer otras demandas que trascenderán el puro orden hobbesiano o decisionista. 


\section{LA CONSOLIDACIÓN DEL NUEVO ORDEN. EL PLAN DE CONVERTIBILIDAD}

Hacia fines de enero de 1991, el malestar social generado por la imposibilidad de controlar la creciente tasa de inflación, llevarán al Gobierno a implementar una paridad cambiaria 1 a 1 de la moneda nacional con el dólar. Luego de la aprobación en ambas Cámaras, el 1 de abril de 1991 entrará en vigencia la llamada Ley de Convertibilidad (Ley 23.928). Esta ley obligaba al Gobierno a que hubiere una equivalencia entre la base monetaria y las reservas de oro y divisas del Banco Central. Al mismo tiempo, impedía emitir moneda que superara el respaldo en reservas. Dado que el tipo de cambio estaba sobrevaluado, el Estado se vio en la obligación de buscar fuentes de financiamiento externo que permitieran el ingreso de divisas. Esto lo resolvió mediante la apertura y desregulación económica y la privatización compulsiva de las empresas públicas y, luego, mediante el endeudamiento externo (Basualdo, 2006). El régimen cambiario no era, por lo tanto, como algunos creen, una «simple ley» (Barros, 2002: 170), sino que implicaba una verdadera reforma estructural, íntimamente ligada a una multiplicidad de políticas que permitían su sostenimiento (Azpiazu, 1995; Kulfas, 2001: 181). En este sentido, resulta más adecuado denominarlo, y así lo haremos desde ahora, Plan de Convertibilidad ${ }^{19}$.

Con los recursos provenientes de las privatizaciones y la apertura comercial y financiera, el Plan de Convertibilidad comenzó a dar paulatinamente sus primeros frutos: se produjo una importante desaceleración inflacionaria, las firmas cesaron las remarcaciones preventivas de precios, los depósitos comenzaron a retornar a los bancos y reapareció el crédito. De este modo, se logrará satisfacer lo que en los hechos era la principal demanda social: la desaparición del «impuesto inflacionario» y la estabilización efectiva de la economía ${ }^{20}$ :

Este Presidente [...] nos ha llevado a la conquista de algo que parecía casi imposible para esta Argentina: la estabilidad económica. En este país aparentemente agotado en marchas y contramarchas, de ineptitud funcionarial, de inmoralidad administrativa, la estabilidad constituye un logro histórico.

19 En otras palabras, si bien el 1 a 1 significará literalmente una ley, simbolizará muchos más significantes (véase Todorov, 1982). Esto, por otra parte, se contradice con la supremacía que adquieren los significantes sobre el significado o concepto concreto. Al respecto, véase especialmente Laclau (2005).

${ }^{20}$ En efecto, encuestas realizadas poco después de las elecciones del '89 muestran que un 64,7\% de los votantes de Menem lo habían elegido para que solucionara la crisis económica (Página 12, 28/05/89). 
Así, derrotamos la hiperinflación y tomamos por las astas un Estado herrumboso para transformarlo eficientemente. Las arcas vacías comenzaron a llenarse con la recaudación fiscal. La moneda empezó a tener valor real, luego de años de haber sido papel de colores. En definitiva, resucitamos un país que parecía condenado al olvido de los que viven dentro y fuera de él (29/08/91: 159).

La Ley de Convertibilidad ha otorgado estabilidad a la economía argentina, manteniendo una paridad cambiaria que no sufre alteraciones, y registrando los índices de inflación más bajos de hace muchísimos años (18/11/91: 126).

En ese contexto, creemos que el Plan de Convertibilidad representará lo que denominaremos una «Promesa Plena».

\section{LA «PROMESA PLENA»}

En un excelente artículo, escrito a comienzos de 1990 y publicado unos años después, Claudia Hilb (1994) se sitúa en el levantamiento militar de Semana Santa de abril de 1987. En ese momento, el por entonces presidente, Raúl Alfonsín, había afirmado que «La casa está en orden» al tiempo que «pactaba» con los militares la ley del «perdón» o Ley de Obediencia Debida. Es a partir de dicho suceso, y la consecuente ruptura del «pacto democrático» que había prometido defender (Acuña y Smulovitz, 1995), en el que se «reinstala un tipo de interpretación en términos de «pantalla»: la «realidad no está nunca allí donde parece estar, lo visible es una pantalla, sus guardianes, los políticos» (Hilb, 1994: 11). Según Hilb, la consecuencia de esto será el vaciamiento de la promesa y el consiguiente descreimiento en la palabra política (Hilb, 1994: 9). Ello se debe a que, como ya lo había analizado Austin (1998), prometer no es sólo enunciar una promesa, sino que, dado su carácter performativo, implica necesariamente realizarla. Así, cuando las promesas ya no son cumplidas, dejan de tener sentido (Hilb, 1994). En ese contexto, Menem no hará más que algunas promesas vagas durante la campaña del '89. Poco antes de las elecciones, dirá: «Expreso un compromiso, que no es una promesa» (Página 12, 04/05/89).

Frente a esta situación de descreimiento general, la autora advertía que la promesa corría el riesgo de desvirtuarse hacia dos formas diferentes. Por un lado, podía terminar convirtiéndose en una «palabra hueca», es decir, «el descreimiento en un espacio de aparición público, en un mundo en común», la promesa entendida únicamente como un «engaño encubridor». Por otro lado, podía derivar en una «palabra plena», esto es, una palabra que «se 
eleva contra la imprevisibilidad», que instaura la «certeza absoluta». Mientras que la «promesa hueca» ya no cree en la promesa, la «promesa plena» pretende cubrir todo el espacio del futuro [...] subordinando en forma absoluta lo impredecible a lo dicho hoy» (Hilb, 1994: 9).

Creemos que la crisis de la palabra política dejó como consecuencia la existencia de una «palabra hueca». En ese contexto, ya desde el primer día de asumir, el discurso de Menem contraponía la supremacía de los hechos frente a la «retórica» de las palabras:

Como diría Eduardo Mallea, uno de los grandes pensadores, la Argentina fue hasta ayer un «desierto de palabras». Yo les aseguro que a partir de este instante, la Argentina inicia la independencia de la retórica [...]. Vamos a hablar con los hechos, y no tan sólo con los discursos (08/07/89: 20).

No quiero detenerlos o entretenerlos más, he dicho una y mil veces que la Argentina está cansada de palabras y Argentina y este gobierno nacional ha optado por la contundencia de los hechos y no por el halago de las palabras, que muchas veces terminan en promesas totalmente incumplidas y en gestos de hipocresía y demagogia que no se compadecen con lo que quiere Argentina y pretende el mundo (13/07/92: 56).

Es por eso que más vale siempre predicar con el ejemplo, predicar con las obras, con los hechos, y terminar con la retórica, que puede ser muy linda, muy bonita, llena de palabras hermosas, pero totalmente vacía, sin contenido, sin afecto, sin amor, sin fe, sin esperanza (20/08/93: 194).

En contraposición a la retórica vacía, el éxito del Plan de Convertibilidad actuará como una «Promesa Plena», la instauración del reinado de una «realidad», un «Grado cero», que se mostraba «de forma inmediata $»^{21}$ (Hilb, 1994: 16):

Todos sabemos que las palabras no alcanzan. No alcanzan si no van acompañadas de hechos concretos. Concretísimos. Porque es en los hechos desde donde, entre todos, hemos empezado a probar la más irreversible vocación de cambio. Es en los hechos donde se está dando la transformación argentina (25/07/91: 65).

Evidentemente hay un cambio en la historia, hemos dado un giro copernicano en nuestras cosas; pero no tan sólo a partir de las palabras, porque de retórica y de palabras la gente está cansada, sino a través de la contundencia de los hechos (12/05/93: 254).

${ }^{21}$ La noción de Grado cero, originariamente propuesta por el Grupo U, hace referencia a un discurso unívoco, no figurado y, por lo tanto, «no retorizado» (véase Soto, 2005: 30-31). 
Porque, como decía Perón, «Mejor que decir es hacer y mejor que prometer es realizar»:

Llego a este encuentro con la voluntad de expresar mi convicción en los hechos antes que en las simples palabras. Llego para hablar con definiciones que se respaldan en hechos concretos y no solamente en buenas frases, porque éste es el tiempo del hacer primero y del decir después (25/09/91: 221).

Lo importante es esto, es la obra que admiramos, tocamos, palpamos y vivimos. Esto es lo importante, no las palabras del Gobernador, del Presidente. No, lo importante son los hechos. Por eso siempre, parafraseando al general Perón, mejor que decir es hacer y mejor que prometer es realizar (22/08/93: 217).

Esto se relacionaba, al mismo tiempo, con el otro gran latiguillo de la tradición peronista: «La única verdad es la realidad»:

Yo voy a ser muy breve hoy porque, como dijo el General Perón, la elocuencia política no es sino la expresión de la verdad en el menor número de palabras. $Y$, en efecto, la verdad debe hablar sin artificios. Con esa elocuencia irrebatible de los hechos [...]. Tal como lo estamos viendo: en la más real de las realidades y la más esperanzada de las esperanzas (26/08/91: 143-144).

Quiero ser breve a partir de hechos concretos porque, como todos ustedes saben, se han dado realizaciones ciertas durante estos últimos tiempos, realizaciones que hemos encarado con energía, equilibrio y audacia. Realizaciones que trascienden la oratoria, que superan los simples proyectos y que son verdaderas realidades (06/11/91: 79).

Esta «real-realidad» de las cosas se objetivaba, a su vez, mediante la «evidencia» de los indicadores macroeconómicos favorables:

Cuando llegamos al Gobierno, siempre es bueno repetirlo, teníamos una inflación de más del 200\%. El mes pasado tuvimos una inflación del 0,8\% $y$ en los tres primeros meses del año no superamos el 2,5\% de inflación. Estos son hechos, son realidades. Ésta es la verdad, y la única verdad es la realidad. Alguien decía esto con profundo conocimiento de las cosas (06/04/93: 147).

Hay una cifra que yo no he citado: la disminución, por ejemplo, de los índices de pobreza. Muchos políticos y muchos hombres no políticos de otros sectores de la comunidad, han hecho referencia permanentemente a este tema de la pobreza en la República Argentina. La estamos combatiendo, pero no en base a la demagogia, sino con hechos ciertos, reales. Cuando no- 
sotros llegamos al gobierno, el índice de pobreza estaba cerca del 30 por ciento; pobreza estructural y el índice de pobreza marginal, que ya prácticamente es la miseria, en un 9 por ciento; actualmente el índice de pobreza estructural [...] (está) en un 12 por ciento y el índice de pobreza marginal, en un 2,5 por ciento (22/12/93: 255$)$.

En efecto, la sobrevaluación de la moneda, producto del Plan de Convertibilidad, logrará un fuerte incremento del consumo. En ese contexto, se reducirá la pobreza y se incrementarán los salarios, fuertemente deprimidos en el período anterior (Gerchunoff y Torre, 1996). De esta manera, el éxito del Plan trascenderá el logro de la estabilidad, para incluir también a los significantes «crecimiento», «desarrollo» y una «moneda fuerte»:

¿Qué es lo que hemos conseguido? [...]. Nada más ni nada menos que la estabilidad, el desarrollo, el crecimiento, que han llevado a nuestro país a ser considerado como uno de los ejemplos en el mundo entero (10/12/93: 225226).

Estamos cambiando el rumbo de la historia en la República Argentina, porque se acabó la Argentina de la especulación, del desorden, del caos [...]. Ustedes recordarán que antes vivíamos pendientes del dólar; ahora, gracias a Dios, tenemos una moneda fuerte y una economía sana, y vivimos pendientes de lo nuestro, de nuestra economía, de nuestra estabilidad y de nuestra Convertibilidad (29/04/93: 202).

Y será nuevamente en la evidencia de los hechos donde se objetivará esta «realidad»:

En sólo cuatro años y medio de gobierno, hemos conseguido esta transformación que, por ejemplo, ha llevado a la República Argentina a colocarse entre los cuatro países que más crecieron en estos últimos tres años, en lo que hace a su Producto Bruto Interno. Ha subido la producción, reitero, ha crecido en forma significativa el consumo, han disminuido los índices de pobreza y se acrecienta la demanda laboral. Estos son los logros que hemos conseguido (24/11/93: 176).

Los índices de producción y de consumo que hacen al comercio, han aumentado. Esto nadie lo puede negar. El PBI ha crecido desde 1990 a la fecha casi un 26\% y hemos marginado definitivamente esos verdaderos flagelos que eran la inflación y la hiperinflación en la República Argentina (10/11/93: 104-105). 
En efecto, la «contundencia de los hechos» no hacía más que «hablar por sí mismos» ${ }^{22}$ :

El resultado de este plan económico habla por sí mismo. Nadie puede decir que no estamos mucho mejor que el año pasado. La industria está empezando a crecer, impulsada por un panorama prometedor en todo sentido. La Bolsa ha alcanzado, como todos ustedes bien saben, niveles históricos. Han comenzado a ingresar capitales extranjeros, convocados no por las buenas palabras, sino por una realidad fáctica que se hace cada día más visible a la comunidad internacional (29/08/91: 160).

Aquí los números hablan más que mil palabras. No mienten. No engañan. En los precios al consumidor, durante el semestre abril-septiembre, el promedio mensual de la tasa de inflación ha sido del 2,9\%. En octubre fue del 1,4\%. Y en noviembre, el histórico 0,4\% que ustedes ya conocen (10/12/91: 162).

Se trataba, por lo tanto, de un discurso legitimado en la performatividad de los hechos: «Nosotros no nos vamos en promesas, lo que decimos lo cumplimos» (Discurso del 29/04/93: 202). De este modo, frente a la inevitable brecha entre el enunciado y la enunciación, la pregunta sobre el Che voui? (¿qué quiere?) del discurso del Otro (Zizek, 1992), la performatividad de su «palabra plena» actuaba como una respuesta que le permitía referirse a las «cosas» en un «Grado cero ${ }^{23}$, como una realidad que, eludiendo la imposibilidad del metalenguaje, se mostraba de forma transparente, sin deseos ni intereses ocultos. Así, podrá decir: «mis palabras son sinceras. Aquí no hay ningún tipo de trampa ni expresión fuera de lugar» (Discurso del 27/09/93: 461-462).

Al tiempo que la performatividad de su discurso igualaba, del mismo modo que lo hacía Perón, la promesa al hecho, sus adversarios se quedaban meramente en las promesas vacías:

Nuestros adversarios prometen, nosotros realizamos, cumpliendo con el mandato histórico de Perón y Evita (citado en página 12, 12/05/95).

De esta manera, apelando al relato «objetivo» $\mathrm{y}$ «transparente» de los hechos, el discurso de Menem lograba transformar el Plan en una realidad incon-

22 No obstante este tipo de «descripción narrativa de la realidad», que parece «hablar por sí misma», resulta interesante notar también los acontecimientos que son excluidos o dejados fuera. En este caso, el enunciador no se referirá al incremento de la desocupación, la precarización laboral y la desigualdad que su Plan económico estaba generando. Sobre el particular, véase White (1992: 19-25).

${ }^{23} \mathrm{Cf}$. lo señalado en la nota 21 . 
trastable de sentido común ${ }^{24}$. Pero, más importante aún, es que esta contundencia desplegada en la «evidencia», en una fuerza en la que, en palabras de Menem, «los números hablan» (Ámbito Financiero, 10/07/91), le permitía al enunciador «desenmascarar» (Windisch et al., 1993: 112) a sus adversarios, aquellos «demagogos»y «agoreros de siempre» que sólo pretenden «hacer política»:

Cuando se nos habla de este modelo y se nos dice de la falta de sensibilidad del mismo, evidentemente se trata de interpretaciones de mala fe, o se trata de quienes, desde la demagogia, pretenden hacer política. Los números dicen totalmente lo contrario a lo que aseveran estos pocos hombres de la política nacional o de otros sectores de la comunidad organizada (22/12/93: 252).

Pueden continuar agraviándonos, pueden continuar difamándonos. A cada agravio, a cada difamación, a cada insulto, una obra, una realización, un hecho. Mejor que decir es hacer, mejor que prometer es realizar. A eso vamos y ése es nuestro futuro, nuestro destino (03/10/93: 134).

Ésa ha sido nuestra respuesta de siempre [...] ;Una realidad por cada mentira! (Juan D. Perón, 01/05/50. Citado en Verón y Sigal, 2003: 78).

Al mismo tiempo, el enunciador evitaba el surgimiento de posibles disidencias, ya que si alguien expresaba en pleno auge del consumo, el crecimiento y la estabilidad económica que los beneficios del Plan eran imaginarios, resultaba irremediablemente excluido de la sociedad por estar «escindido de la realidad $»^{25}$ :

¿Hay algún argentino en su sano juicio que quiera volver a 1989, con esta estabilidad económica, con este cambio que estamos produciendo y con la capacidad del salario que va en aumento? (citado en Clarín, 01/08/91).

Los resultados están a la vista, ahora, ¿quién en su sano juicio puede cambiar un modelo que ha sacado a la Argentina de una crisis prácticamente letal de décadas para colocarla como uno de los países de mayor crecimiento en nuestro planeta? (22/12/93: 259).

La apelación a una supuesta realidad objetiva marcaba, así, una continuidad y, a la vez, un punto de inflexión con el peronismo tradicional. La

${ }^{24}$ En efecto, como señala Barthes (1991: 239) acerca del mito, cuando se comprueba algo sin explicarlo, «se está a un paso de encontrarlo natural, que cae por su propio peso» y ello en razón de que «un mundo desplegado en la evidencia, funda una claridad feliz: las cosas parecen significar por sí mismas».

25 En este sentido, podemos decir que quedaba establecido una especie de «principio de exclusión» que separaba lo que se consideraba «razón», apoyar las reformas, de lo que se veía como «locura», rechazarlas (al respecto, véase Foucault, 1973: 12-13). 
continuidad residía en el hecho que, al igual que afirmaba Perón, «La única verdad es la realidad». La inflexión, por su parte, se debía a que mientras que en el peronismo tradicional el enemigo era la «vieja oligarquía» y los «intereses extranjeros opuestos a la República» (Verón y Sigal, 2003: 78), en el caso de Menem el Otro ya no era un enemigo de la nación, sino aquellos rezagados que no lograron comprender la «realidad de lo real» (Hilb, 1994):

Los acontecimientos que nos han preocupado no son producto de lo que se denomina ajuste o reajuste, son producto de la falta de capacidad y de comprensión de lo que ocurre actualmente en el mundo y en la República Argentina, por algunos sectores de nuestra comunidad (22/12/93: 255).

Concepciones de esta naturaleza, en el fondo ocultan un profundo prejuicio político y cultural, aferrado a concepciones del pasado. En algunos casos, aferrado incluso a mentalidades exclusivamente ideologizadas, incapaces de comprender los inmensos cambios que se registran actualmente en todo el mundo (24/10/89: 132).

Como consecuencia de esta visión, prevalecerá un «pensamiento único», transformado en «sentido común», que, incentivado, además, por la inevitabilidad de los cambios tecnológicos que caracterizan a la modernidad, y por la metáfora equivalencial $1=1$ que simbolizará el Plan $^{26}$ generará un mecanismo psicológico, una especie de «Grado 1» no reflexionado ${ }^{27}$, que impedirá ver las consecuencias políticas, económicas y sociales que estaba produciendo el nuevo orden e incapacitará pensar en proyectos alternativos, al tiempo que promoverá la apatía política y el conformismo (García Delgado, 1994).

\section{CONCLUSIONES}

En el transcurso de este trabajo nos hemos propuesto analizar las estrategias discursivas de la enunciación menemista. Para ello, abordamos su re-

${ }^{26}$ En efecto, la Convertibilidad de la moneda nacional con el dólar estadounidense se simbolizará mediante una metáfora que representará una equivalencia $1=1$ entre ambas monedas. Sobre la noción de metáfora y su funcionamiento conceptual, véanse Le Guern (1976: 18) y Lakoff y Johnson (1998).

27 El Grado 1 hace referencia, según Steimberg, a «aquella retorización, consolidada socialmente, que pasa a incorporarse a las previsibilidades de un intercambio discursivo y queda circunscripta a una determinada área de desempeño». La eficacia de estas metáforas reside en su «alto grado de convencionalidad (resultado de su repetición)» que «hace que se asuma, sin reflexionar siquiera, la presuposición que la habilita» (citado en Soto, 2005: 32-33). En este caso, la Convertibilidad, al estar establecida mediante un marco legal, borrará en su repetición diaria las huellas de su institución contingente y, de esta manera, se la asumirá sin reflexionarla. 
lación con los dispositivos de enunciación del discurso peronista. De este modo, hemos pretendido trascender las limitaciones que encontramos en la mayoría de los enfoques que investigaron el tema. Partiendo desde un análisis en términos de la dimensión ideológica, pudimos observar que Menem se situó, al igual que Perón, como aquel que venía a unificar a todos los argentinos trascendiendo los intereses particulares. De este modo, y apelando a los clásicos latiguillos peronistas, justificaba su pragmatismo. El conflicto era para el Presidente, al igual que lo era para Perón, signo de un absurdo, de intereses mezquinos e ideologismos particulares o partidistas que llevaban a la disolución del cuerpo social. Por lo tanto, no podía ser aceptado como legítimo. Al mismo tiempo, el enunciador se ubicaba, del mismo modo que Perón, por fuera de esos intereses mezquinos, como un representante de los intereses de la Patria que venía a hacer cirugía mayor sin anestesia para «sanar» al organismo social. Este mecanismo, que pretendía despolitizar las decisiones tomadas y, al mismo tiempo, deslegitimar a sus adversarios, no se estructuró, sin embargo, como un discurso tecnocrático. Tampoco lo hizo como un «modelo de llegada» o como un «outsider» de la política. Se trataba, en cambio, de un dispositivo basado en la legitimación mediante la «contundencia de los hechos». Para el éxito de esta estrategia, que sólo pudo ser consolidada a partir de la instauración del Plan de Convertibilidad, resultaría crucial la mostración como evidente de los hechos, ya sea mediante la incorporación de los indicadores económicos, ya sea mediante el detalle de los éxitos logrados. En efecto, el Plan de Convertibilidad, a partir de la paridad del peso con el dólar, permitió alcanzar el logro de una moneda sólida, un fuerte crecimiento de la economía, que lo ubicaba entre los países que más crecían en todo el planeta, la presencia de un sostenido desarrollo, materializado a través del incremento del consumo, de la inversión y de una importante reducción de la pobreza, y una extendida estabilización económica y política, que habían permitido terminar con el «cáncer» de la hiperinflación y consolidar un orden social, en contraposición al caos y los saqueos del alfonsinismo. A través de esta «única verdad» que era la «realidad» tangible e incontrastable de los hechos, y apelando además a la eficacia de la simbolización metafórica que representaba la equivalencia 1 a 1 entre ambas monedas, el Presidente lograba dos cometidos. Por un lado, objetivaba al Plan de Convertibilidad como una Promesa Plena, como una «real realidad» que, frente a la crisis de la palabra política, se mostraba de forma inmediata. Por el otro, lograba la exclusión de sus adversarios, a quienes acusaba, ya sea de tener intereses particulares o partidistas, ya sea de tener ideologismos de un pasado inexistente o de ser rezagados que no lograron comprender la realidad. 


\section{REFERENCIAS BIBLIOGRÁFICAS}

ABOY CARLÉS, G. (2001). Las dos fronteras de la democracia argentina. La reformulación de las identidades políticas de Alfonsín a Menem. Rosario: Homo Sapiens.

- (2003). «Repensando el populismo». Política y Gestión (Rosario) 4, 9-34.

ACUÑA, C. y SMULOVITZ, C. (1995). «Militares en la transición argentina: del gobierno a la subordinación constitucional». En La nueva matriz política argentina, Carlos Acuña (comp.), 153-202. Buenos Aires: Nueva Visión.

AUSTIN, J. (1998). Cómo hacer cosas con palabras. Barcelona: Paidós.

AZPIAZU, D. (1995). «La industria argentina ante la privatización, la desregulación y la apertura asimétricas de la economía. La creciente polarización del poder económico». En El desarrollo ausente, Daniel Azpiazu y Hugo Nochteff (eds.), 157-233. Buenos Aires: Tesis-Norma-FLACSO.

BARROS, S. (2002). Orden, democracia y estabilidad. Discurso y política en la Argentina entre 1976 y 1991. Córdoba: Alción.

BARTHES, R. (1970). S/Z. París: Du Seuil.

— (1991). Mitologías. Buenos Aires: Siglo XXI.

BASUALDO, E. (2006). Estudios de historia económica argentina. Desde mediados del siglo XX a la actualidad. Buenos Aires: Siglo XXI-FLACSO.

BENJAMÍN, W. (2004). «Tesis sobre la historia». En Tesis sobre la historia y otros fragmentos, Bolívar Echeverría (ed. y traductor). México: Contrahistorias.

BENVENISTE, E. (1980). Problemas de lingüística general. México: Siglo XXI.

BORÓN, A. (1991). «Los axiomas de Anillaco. La visión de la política en el pensamiento y en la acción de Carlos Saúl Menem». En El Menemato. Radiografía de 2 años de gobierno de Carlos Menem, AA.VV., 47-83. Buenos Aires: Letra Buena.

- (1995). «El experimento neoliberal de Carlos Saúl Menem». En Peronismo y menemismo, AA.VV., 59-80. Buenos Aires: El Cielo por Asalto.

CANELO, P. (2002). La construcción de lo posible: identidades y política durante el menemismo. Argentina, 1989-1995. Buenos Aires: Documento de trabajo de FLACSO Argentina. 
CAVAROZZI, M. (1997). Autoritarismo y democracia (1955-1996). La transición del Estado al mercado en la Argentina. Buenos Aires: Ariel.

CHERESKY, I. y BLANQUER, J. M. (2003). De la ilusión reformista al descontento ciudadano. Rosario: Homo Sapiens.

DE SAUSSURE, F. (1961). Curso de lingüística general. Buenos Aires: Losada.

DE ÍPOLA, E. (1983). Ideología y discurso populista. Buenos Aires: Folios.

DUCROT, O. (1986). «Esbozo de una teoría polifónica de la enunciación». En El decir y lo dicho. Polifonía de la enunciación, 175-239. Barcelona: Paidós.

FABBRI, P. (2000). El giro semiótico. Barcelona: Gedisa.

FAIR, H. (2007). Identidades y representación. El rol del Plan de Convertibilidad en la consolidación de la hegemonía menemista (1991-1995). Tesis de Maestría para aplicar al grado de Maestría en Ciencias Sociales, Facultad Latinoamericana de Ciencias Sociales (FLACSO), Sede Argentina, mimeografiado.

- (2008). «La función del significante convertibilidad en la articulación discursiva de la identidad menemista». Question 17. ISSN 1669-6581. Disponible en: http://perio.unlp.edu.ar/question/nivel2/informe_de_investigacion.htm.

FOUCAULT, M. (1973). El orden del discurso. Barcelona: Tusquets.

GARCÍA DELGADO, D. (1994). El cambio de relaciones Estado-sociedad en el proceso de modernización en Argentina. Instituto de Investigaciones de la Facultad de Ciencias Sociales, Universidad de Buenos Aires, mecanografiado.

GENETTE, G. (1998). Nuevo discurso del relato. Madrid: Cátedra.

GERCHUNOFF, P. y TORRE, J. C. (1996). «La política de liberalización económica en la administración de Menem». Desarrollo Económico 141, 733-768.

GIUSSANI, P. (1990). Menem, su lógica secreta. Buenos Aires: Sudamericana.

GREIMAS, A. J. y COURTÉS, J. (1990). Diccionario razonado de teoría del lenguaje. Madrid: Gredos.

HABERMAS, J. (1994). Teoría de la Acción Comunicativa: Complementos y estudios previos. Madrid: Cátedra. 
HILB, C. (1994). Promesa y política. Promesas traicionadas y transición democrática. Buenos Aires: Secretaría de Gestión Institucional, Universidad de Buenos Aires.

KULFAS, M. (2001). «El rol del endeudamiento externo en la acumulación de capital durante la Convertibilidad». Época 3, 181-216.

LACLAU, E. y MOUFFE, C. (1987). Hegemonía y estrategia socialista. Hacia una radicalización de la democracia. Buenos Aires: FCE.

LACLAU, E. (1993). Nuevas reflexiones sobre la revolución de nuestro tiempo. Buenos Aires: Nueva Visión.

- (1996). Emancipación y diferencia. Buenos Aires: Ariel.

- (2005). La razón populista. Buenos Aires: FCE.

LAKOFF, G. y JOHNSON, M. (1998). Metáforas de la vida cotidiana. Madrid: Cátedra.

LE GUERN, M. (1976). La metáfora y la metonimia. Madrid: Cátedra.

LOZANO, Claudio y FELETTI, Roberto (1991). «La economía del menemismo. Cambio estructural, crisis recurrentes y destino incierto». En $\mathrm{El}$ Menemato. Radiografía de dos años de gobierno de Carlos Menem, AA.VV., 119-169. Buenos Aires: Letra Buena.

LYOTARD, J. F. (1992). La condición postmoderna. Buenos Aires: Amorrortu.

MAINGUENEAU, D. (1976). Initiation Aux methods de l'analyse du discours. París: Hachette.

MANONNI, O. (1994). «Un Mallarmé para los analistas». En El trabajo de la metáfora, J. Kristeva et. al., 15-41. Barcelona: Gedisa.

MARTÍNEZ, O. (1991). «El escenario: febrero-julio de 1989. Terrorismo económico y desestabilización política». En El Menemato. Radiografía de dos años de gobierno de Carlos Menem, AA.VV., 15-46. Buenos Aires: Letra Buena.

MARTUCELLI, D. y SVAMPA, M. (1997). La plaza vacía. Las transformaciones del peronismo. Buenos Aires: Losada.

MENEM, C. y DUHALDE, E. (1989). La revolución productiva. Buenos Aires: Peña Lillo. 
NOVARO, M. (1994). Pilotos de tormentas: crisis de representación y personalización de la política en Argentina. 1989-1993. Buenos Aires: Letra Buena.

NUN, J. (1994). «Populismo, representación y menemismo». Sociedad 5, 93 121.

PALERMO, V. y NOVARO, M. (1996). Política y poder en el gobierno de Menem. Buenos Aires: Norma-FLACSO.

PALERMO, V. y TORRE, J. C. (1992). A la sombra de la hiperinflación. La política de reformas estructurales en Argentina. Santiago de Chile: CEPAL.

PARRET, H. (1995). De la semiótica a la estética. Buenos Aires: Edicial.

POULANTZAS, N. (1971). Poder político y clases sociales en el Estado capitalista. Buenos Aires: Siglo XXI.

PORTANTIERO, J. C. (1995). «Menemismo y peronismo: continuidad y ruptura». En Peronismo y menemismo, AA.VV., 101-117. Buenos Aires: El Cielo por Asalto.

RAWLS, J. (1972). A Theory of Justice. Clarendon: Oxford Press.

SARTORI, G. (1992). Partidos y sistema de partidos. Madrid: Alianza.

SIDICARO, R. (1995). «Poder político, liberalismo económico y sectores populares». En Peronismo y menemismo, AA.VV., 119-156. Buenos Aires: El Cielo por Asalto.

SEGRE, C. (1985). Principios del análisis del texto literario. Barcelona: Crítica.

SOTO, M. (2005). «Operaciones retóricas». Cuadernos de la Carrera de Ciencias de la Comunicación Social, Facultad de Ciencias Sociales, Universidad de Buenos Aires: mimeografiado.

STEIMBERG, O. (1998). Semiótica de los medios masivos. Buenos Aires: Atuel.

TODOROV, T. (1982). «Sinécdoques». En Investigaciones retóricas II, AA.VV., 45-56. Barcelona: Ediciones Buenos Aires.

TORRADO, S. (1994). Estructura social de la Argentina: 1945-1983. Buenos Aires: De la Flor.

TORRE, J. C. (1991). "América Latina: el proceso de la democracia en tiempos difíciles». Estudios Políticos 74, 145-161. 
VERÓN, E. (1985). «El discurso tecnocrático», fragmentos tomados de Le corps du president (Traducción de la cátedra de «Cultura y lenguajes políticos», Ques-Sagol, Carrera de Ciencia Política, Facultad de Ciencias Sociales, Universidad de Buenos Aires), Ivry sur Seine, mimeografiado.

- (1987a). «La palabra adversativa. Observaciones sobre la enunciación política». En El discurso político. Lenguaje y acontecimientos, AA.VV., 1326. Buenos Aires: Hachette.

— (1987b). La semiosis social. Buenos Aires: Gedisa.

- (1995). Semiosis de lo ideológico y el poder. Buenos Aires: Universidad de Buenos Aires.

VERÓN, E. y SIGAL, S. (2003). Perón o muerte. Los fundamentos discursivos del fenómeno peronista. Buenos Aires: Legasa.

WAISBORD, S. (1995). El gran desfile. Campañas electorales y medios de comunicación en la Argentina. Buenos Aires: Sudamericana.

WHITE, H. (1992). El contenido de la forma. Barcelona: Paidós.

WINDISCH, U. et al. (1993). Comunicación y argumentación política cotidiana en democracia directa. París: Universidad de Ginebra.

YANNUZZI, M. (1995). La modernización conservadora. El peronismo de los '90. Rosario: Fundación Ross.

ZIZEK, S. (1992). El sublime objeto de la ideología. Buenos Aires: Siglo XXI.

\section{FUENTES}

- Diarios Clarín, La Nación y Página 12 (Argentina).

- INDEC (1998): Anuario Estadístico de la República Argentina, Instituto Nacional de Estadísticas y Censos, vol. 14.

- Página oficial del INDEC: www.indec.gov.ar.

- Discursos oficiales del Presidente de la Nación, Dr. Carlos Saúl Menem, Dirección General de Difusión, Secretaría de Medios de Comunicación, Presidencia de la Nación, República Argentina (varios tomos). 